\title{
SÍNTESE E CARACTERIZAÇÃO DE CARVÃO ATIVO CONTENDO NANOPARTÍCULAS DE PRATA PARA UTILIZAÇÃO EM EQUIPAMENTO DE PROTEÇÃO RESPIRATÓRIA
}

\author{
SYNTHESIS AND CHARACTERIZATION OF ACTIVATED CARBON WITH SILVER \\ NANOPARTICLES FOR USE AS RESPIRATORY PROTECTION EQUIPMENT
}

\author{
Letícia Saccol Togny ${ }^{1}$, Fernando Dal Pont Morisso², Ana Paula Becker³, \\ Tiago Moreno Volkmer ${ }^{4}$ e Diogo Kramer Topolski ${ }^{5}$
}

\section{RESUMO}

A busca por informações e orientações quanto ao tipo e a utilização de equipamentos de proteção respiratória (EPR'S) está ampliando-se nas atividades laborativas que abrangem exposições biológicas. Podendo essas, ocasionarem doenças infectocontagiosas transmitidas por bactérias, fungos e vírus. Atualmente os EPR'S são confeccionados por camadas de tecidos não tecidos, conhecidos popularmente como TNT. Essas camadas são revestidas de carvão ativado (CA) para aumentar a adsorção superficial do material. Porém, estes EPR'S não protegem o usuário da exposição em caráter biológico, fazendo com que as bactérias ultrapassem o carvão ativado. Assim, neste trabalho objetiva-se incorporar nanopartículas de prata (NPAg) em uma malha de CA para obter o enriquecimento das propriedades no desempenho da adsorção de particulados e/ou bioaerossóis em ambientes laborais caracterizados biologicamente. Dessa forma, o objetivo deste trabalho foi obter uma malha de CA contendo NPAg e testar sua propriedade bactericida contra bactérias do tipo Staphylococcus aureus. A metodologia empregada permitiu a obtenção de uma malha de CA contendo as NPAg. Por Microscopia eletrônica de varredura verificou-se que o CA manteve a morfologia do tecido de algodão após os processos de carbonização e ativação. A síntese das NPAg com tamanho de cristalito de $30,9 \mathrm{~nm}$ foi confirmada por difração de raio X e EDS. Os CA's contendo NPAg demonstraram uma maior capacidade de inibir a formação de biofilmes de bactérias do tipo Staphylococcus aureus.

Palavras-chave: hexametilmetilenotetramina, ensaio de formação de biofilme, Staphylococcus aureus.

\section{ABSTRACT}

The search for information and guidance about the correct use and selection of respiratory protection equipment $(R P E)$ is growing in importance in the labor activities that comprehends biological exposure which can promote infectious and contagious diseases transmitted by bacteria, fungi and virus. The RPE's are composed of an activated carbon tissue layer in the middle of two layers of tissue non-tissue. The function of the AC layer is to increase the surface area of the mask. However, this RPE don't give full protection to the users against biological agents, in such a way that the bacteria can trespass through the activated carbon layer. So, this work aims to incorporate silver nanoparticles into an AC fabric and test its bactericide properties against Staphylococcus aureus bacteria. The employed methodology was successful to obtain an AC structure from a cotton fabric containing silver nanoparticles. Scanning Electron Microscopy analysis confirmed that after the

\footnotetext{
1E-mail: letogny@hotmail.com

2 E-mail: morisso@feevale.br

3 E-mail: anapbecker1@gmail.com

4 E-mail: tiagovolkmer@gmail.com

5 E-mail: topolski@gmail.com
} 
carbonization and thermal activation process, the AC maintained the fabric structure. The incorporation of AgNP into the activated carbon, with crystallite size of $30.9 \mathrm{~nm}$ was confirmed by XRD and EDS. The activated carbon containing silver nanoparticles showed a better capability to inhibit the formation of biofilms from Staphylococcus aureus bacteria.

Keywords: hexamethylenetetramine, biofilm formation, Staphylococcus aureus.

\section{INTRODUÇÃO}

As doenças relacionadas à atividade laborativa da população estão em constante elevação, principalmente quando se trata da aspiração de aerodispersóides e/ou bioaerossóis. De acordo com a organização internacional do trabalho (OIT), estima-se que 6500 pessoas morrem diariamente devido a doenças ocupacionais, sendo que 17\% dos casos são relacionados a doenças respiratórias (INTERNACIONAL LABOUR ORGANIZATION). Santana e colaboradores (2016) avaliaram a Implantação e Avaliação do Sistema de Monitoramento da Saúde do Trabalhador de Enfermagem (Simoste), e observaram que dentre os desgastes mais apresentados pelos trabalhadores hospitalares, os biológicos relacionados a doenças do aparelho respiratório corresponderam a 18,6\%.

Para a proteção contra estes agentes de exposição, foram criados meios filtrantes que atenuam essas exposições. A história da evolução dos respiradores teve como marco importante a Primeira Guerra Mundial, na época eles eram confeccionados com tiras de tecido e outros dispositivos considerados filtrantes. Outro tipo de proteção bastante utilizado era um filtro perfurado e preenchido de esponja natural, ou por algum outro tipo de material poroso, saturado com água para purificar o ar quando o mesmo transpassasse esse meio, retendo a fumaça e outros vapores nocivos e irritantes (SPELCE et al., 2018). Atualmente os respiradores são de uso individual, posicionados próximos à zona respiratória do usuário de maneira que esses equipamentos eliminam ou diminuem o risco de exposição indevida a agentes químicos

Os materiais prejudiciais à saúde estão presentes em inúmeros ambientes laborais e são constituídos por um conjunto de poluentes formados por poeiras, fumaças e todo tipo de material sólido e líquido que se mantém suspenso na atmosfera devido ao seu pequeno tamanho (entre 10 a $1000 \mathrm{~nm}$ ), e podem ser denominados de aerodispersóides ou bioaerossóis (CETESB, 2020) Microorganismos patogênicos podem permanecer vivos na superfície dos EPR, dessa forma se faz necessário o desenvolvimento de equipamentos com potencial biocida. (NAKAMURA et al., 2019)

Para colaborar com adsorção e inibição do crescimento de microorganismos nos EPR o uso da nanotecnologia pode se tornar uma grande aliada por permitir a obtenção de materiais com características excepcionais, como melhorias nas propriedades ópticas, magnéticas e mecânicas. Aspectos 
estes, que podem ser aproveitados em diversos ramos da tecnologia (CHEN et al., 2008). O processo de incorporação de nanopartículas de prata (NPAg) em materiais têxteis tem ganhado grande atenção devido à sua alta área superficial e por apresentarem novas propriedades interessantes, especialmente o elevado potencial biocida (MATSUSHITA, 2014). De acordo com Sondi and Salopek-Sondi (2004) o mecanismo de ação da prata em bactérias Gram negativas, como a E. coli, se dá pela acumulação das nanopartículas de prata na parede celular, seguida da liberação de radicais livres que danificam a célula e aniquila a bactéria. O tamanho das NPAg é essencial para a manifestação de efeitos antivirais (NAKAMURA et al., 2019) alguns estudos mostram a eficiência deste nano material contra diversos tipos de vírus como hepatite $\mathrm{B}$, herpes, vírus respiratórios inicial e varíola (GALDIERO et al., 2011). Nanoclusters de $\mathrm{Ag}_{2} \mathrm{~S}$ demonstraram alta eficiência antiviral usando o vírus da diarreiaepidêmicaporcinacomomodelo de corona vírus (DUT et al., 2018).

Atuando simultaneamente com as NPAg, o carvão ativado tem poder adsorvente proveniente da alta área superficial e da presença de variedade de grupos funcionais em sua superfície. Estes grupos funcionais influenciam a reatividade e as propriedades de adsorção do material. O carvão ativo pode ser modificado através de tratamento térmico, oxidação e impregnação com vários compostos orgânicos e inorgânicos (GUILARDUCI et al., 2006).

Tendo o biofilme, por uma definição mais usual, corresponde a uma matriz polimérica de aspecto gelatinoso, aderida a uma superfície sólida, quase sempre imersa em meio líquido, constituída essencialmente por microrganismos, pelas substâncias poliméricas extracelulares que estes excretam e por água (PEREIRA, 2001).

O presente estudo tem como objetivo a obtenção de uma malha de carvão ativo, através da carbonização do tecido de algodão com NPAg para reduzir a formação de biofilme, o qual foi testado em bactérias do tipo Staphylococcus aureus, visando sua utilização em dispositivos que aumentem a proteção do trabalhador em ambiente laboral onde há a exposição a agentes biológicos.

\section{MATERIAIS E MÉTODOS}

Tecido 100\% algodão comercial foi utilizado para obtenção de nanopartículas de prata e a formação de carvão ativado. Os reagentes utilizados foram $\mathrm{NaOH}$ (Nuclear - pureza 98\%), Triton X-100 (Nuclear - conc. 100\%) e de ácido cítrico - $\mathrm{C}_{6} \mathrm{H}_{8} \mathrm{O}_{7}(\mathrm{Synth}-\mathrm{PA})$ para a lavagem e nitrato de prata - $\mathrm{AgNO}_{3}$ (Nuclear - conc. 0,05 mol/L) e hexametilmetilenotetramina - HTMA, $\mathrm{C}_{6} \mathrm{H}_{12} \mathrm{~N}_{4}(\mathrm{Synth}$ - conc. 0,05 mol/L) para a deposição de NPAg. O esquema da figura 1 demonstra as etapas de preparação e caracterização das amostras. 
Figura 1 - Esquema dos procedimentos realizados para preparação e caracterização das amostras.
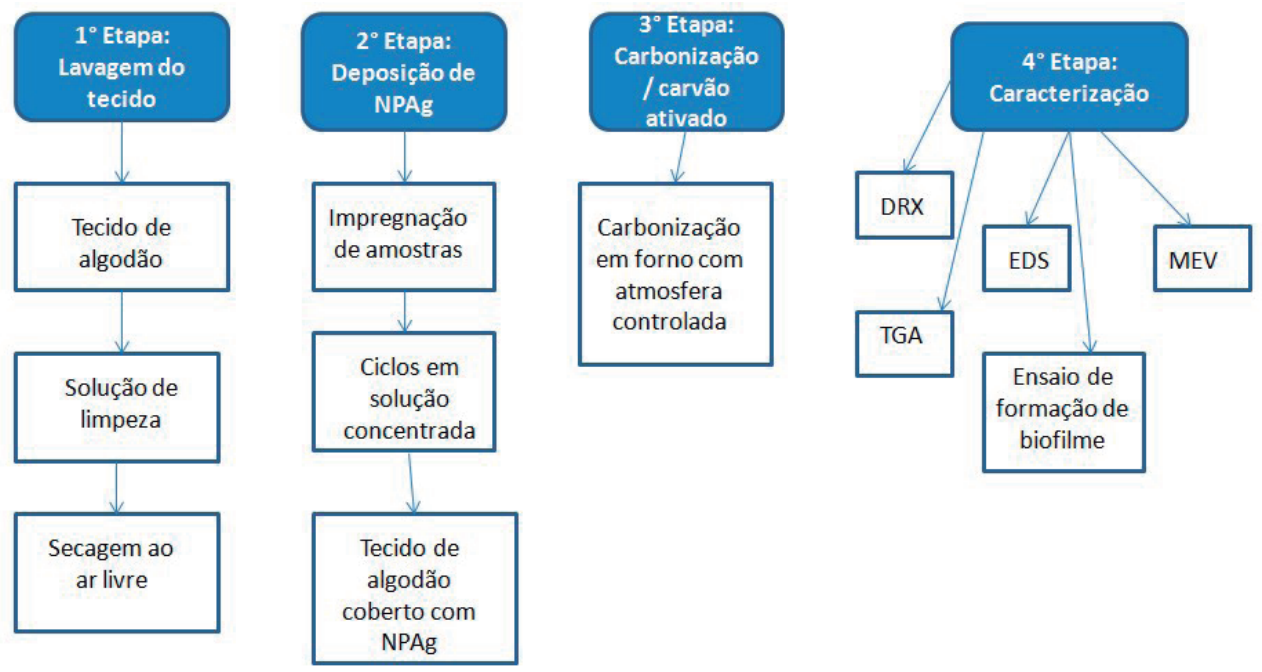

Fonte: Autor

A limpeza do tecido foi efetuada por meio da lavagem em solução contendo 5,0g de $\mathrm{NaOH}$ (Nuclear), 1,5g de Triton X-100 (Nuclear) e 0,75g de ácido cítrico - $\mathrm{C}_{6} \mathrm{H}_{8} \mathrm{O}_{7}$ (Synth) dissolvidos em 500 $\mathrm{mL}$ de água deionizada e aquecidos a $80^{\circ} \mathrm{C}$. As amostras permaneceram em solução durante 1 hora sob agitação mecânica, e, ao fim desta etapa, o material passou pelo enxágue e secagem em temperatura ambiente (ATHAUDA et al., 2014). Posteriormente, visando a deposição das nanopartículas de prata, as amostras têxteis foram tratadas em um ciclo de imersãode 30 minutos. A solução utilizada possui 4,24g de nitrato de prata - $\mathrm{AgNO}_{3}$ (Nuclear - conc. 0,05 mol L-1) e 3,50g de hexametilmetilenotetramina - HTMA, $\mathrm{C}_{6} \mathrm{H}_{12} \mathrm{~N}_{4}$ (Synth - conc. 0,05 mol L-1) como agentes precursores, em 500mL de água deionizada. Finalizado o ciclo, as amostras foram removidas da solução e a água em excesso foi retirada por meio de chapa aquecida (CARÚS, 2017) Na sequência as amostras foram inseridas em um forno tubular marca Jung, com taxa de aquecimento de $10^{\circ} \mathrm{C} / \mathrm{min}$ até $850^{\circ} \mathrm{C}$ com patamar de 1 hora e fluxo de $100 \mathrm{~mL} / \mathrm{min}$ de argônio (HUIDOBRO et al., 2001).

\section{CARACTERIZAÇÕES DAS AMOSTRAS TÊXTEIS E PRECIPITADOS DIFRAÇÃO DE RAIOSX - DRX}

As análises de difração de raios X fornecem informações sobre as fases da estrutura cristalina presentes na amostra sendo assim realizadas em um equipamento Bruker Modelo D2 Phaser, com radiação $\mathrm{Cu} \mathrm{K \alpha}$, e configuração de intervalo de ângulo teta de $5^{\circ}$ a $70,026^{\circ}$, com incremento $0,05^{\circ}$ a cada 1 segundo por passo, alocado na Universidade Franciscana - UFN. Para calcular o índice de Cristalinidade (IC) dos picos encontrados se utilizou o método da subtração de picos, descrito pela fórmula demonstrada na equação 1(PARIKH et al., 2007): 


$$
I C(\%)=\frac{\mathrm{I} 002-\mathrm{IAM}}{\mathrm{I} 002}
$$

Onde, $\mathrm{I}_{002}$ corresponde à intensidade da direção cristalográfica (002) e $\mathrm{I}_{\mathrm{AM}}$ corresponde à intensidade da região amorfa. Já o tamanho de cristalito (D) das nanopartículas de prata foi medido utilizando-se a equação de Debye-Scherrer mostrado na equação 2 (EL-KADER et al., 2019).

$$
D=\frac{k \cdot \lambda}{\beta \cdot \cos (\theta)}
$$

Onde K é a constante de forma, cujo valor é $0,9, \lambda$ é o comprimento de ondas do raio X $(0,15406 \mathrm{~nm})$, $\beta$ é a largura a meia altura (em radianos) e $\Theta$ é o ângulo do pico.

\section{ANÁLISE TERMOGRAVIMÉTRICA - TGA}

Efetuou-se a análise termogravimétrica, visando acompanhar a perda e/ou ganho de massa da amostra em função da temperatura, utilizando o equipamento TGA-50 da marca SHIMADZU, alocado no Laboratório de Materiais Cerâmicos - LACER da Universidade Federal do Rio Grande do Sul - UFRGS. Os parâmetros de análise foram $5^{\circ} \mathrm{C} / \mathrm{min}$, até $700^{\circ} \mathrm{C}$ com atmosfera de nitrogênio.

\section{MICROSCOPIA ELETRÔNICA DE VARREDURA - MEV}

A identificação da morfologia das amostras foi observada em um microscópio eletrônico de varredura da marca JEOL ${ }^{\circledR}$, modelo JEOL JSM -6510LV com acessório de Espectroscopia de Energia Dispersiva (EDS) da marca ThermoScientific, modelo Ultra Dry,alocado no Laboratório de Materiais da Universidade Feevale. Visa à análise qualitativa da amostra para confirmar a formação das partículas e nanopartículas de prata. Todas as amostras foram submetidas à processo padrão de metalização pela aplicação de uma fina camada de ouro.

\section{ENSAIO DE FORMAÇÃO DE BIOFILME}

Objetivando-se analisar a capacidade biocida das amostras, executou-se o ensaio de formação de biofilme das bactérias na superfície dos carvões ativados com e sem nanopartículas de prata, por aplicação da técnica de coloração por cristal violeta contra bactérias do tipo Staphylococcus aureus. O ensaio contou com as etapas de inoculação, cultivo do biofilme e coloração propriamente dita (STEPANOVIC et al., 2007). A linhagem de bactérias Staphylococcus aureus da cultura padrão (ATCC 25904) foi transferida para uma placa contendo ágar sangue e foi incubada por 24 horas em atmosfera ambiente e temperatura de $37^{\circ} \mathrm{C}$. Depois de, se verificar a pureza da cepa, algumas colônias com morfologia idêntica foram suspensas em solução salina $0,9 \% \mathrm{de} \mathrm{NaCl}$. $\mathrm{Na}$ etapa da produção dos biofilmes foi utilizado $100 \mu \mathrm{L}$ das bactérias preparadas no processo de inoculação, e adicionados $2 \mathrm{~mL}$ 
de Trypticasesoybroth (TSB) em cada tubo de ensaio. Posteriormente, foram adicionados aos tubos, frações das amostras com medidas de $1 \mathrm{~cm}$ x $1 \mathrm{~cm}$ de tecido lavado, do carvão ativo e do carvão ativo contendo nanopartículas de prata. Os cultivos foram gerados em triplicata. Como controle negativo foram utilizados $2 \mathrm{~mL}$ de solução salina e $2 \mathrm{~mL}$ de TSB. Já no controle positivo foram adicionados $2 \mathrm{~mL}$ de solução salina, $2 \mathrm{~mL}$ de TSB e $100 \mu \mathrm{L}$ de bactérias. Os tubos de ensaio foram incubados por 24 horas em atmosfera ambiente e temperatura de $37^{\circ} \mathrm{C}$.

Após a incubação para o cultivo dos biofilmes, o conteúdo dos tubos de ensaio foi descartado e cada tubo foi lavado gentilmente com solução salina estéril. Esse passo serve para remover todo o material não envolvido na estrutura do biofilme. Em seguida foram adicionados $2 \mathrm{~mL}$ de corante violeta genciana em cada tubo e os mesmos ficaram em repouso por 15 minutos em temperatura ambiente. Essa etapa tem a função de corar o biofilme formado. Passados os 15 minutos, o conteúdo do tubo foi desprezado e os tubos foram lavados 2 vezes com $2 \mathrm{~mL}$ de solução salina estéril. Para fixar o biofilme após coloração, foi adicionado $2 \mathrm{~mL}$ de metanol (Synth, conc. 99,85\%) a cada tubo e eles ficaram em repouso por mais 20 minutos em temperatura ambiente. Finalmente, o metanol foi retirado e para eluir o biofilme para posterior leitura em espectrofotômetro, se adicionou $3 \mathrm{~mL}$ de etanol (Synth, conc. 99,3\%) em cada tubo e estes permaneceram em repouso por 30 minutos em temperatura ambiente. A densidade ótica de cada tubo de ensaio foi medida em um espectrofotômetro marca INSTRUTHERM (MODELO UV-1000A), com comprimento de onda de $570 \mathrm{~nm}$.

\section{RESULTADOS E DISCUSSÃO}

\section{DIFRAÇÃO DE RAIO X - DRX}

As amostras de 100\% algodão utilizadas nos ensaios de caracterizações foram adquiridas no comércio local, possuindo gramatura de $108 \mathrm{~g} / \mathrm{m}^{2}$. Elas foram submetidas a um processo de lavagem, visando à remoção de impurezas. A Figura 2 a mostra os difratogramas das amostras de algodão cru (antes da lavagem) e do algodão lavado, ao se analisar este difratograma, foram encontrados picos encontrados em posição similar aos da ficha do ICDD PDF 050-2241, que representa a celulose nativa tipo $\mathrm{I}\left(\mathrm{C}_{6} \mathrm{H}_{10} \mathrm{O}_{5}\right) n$ (PARIKH et al., 2007). Percebe-se que após a lavagem houve um aumento na intensidade do pico correspondente ao plano cristalográfico (002), representa um acréscimo no valor de cristalinidade de $79,7 \%$ para $82,7 \%$, o que pode ter ocorrido devido à remoção das impurezas presentes no tecido de algodão cru. Parikh e colaboradores (2007) mediram o índice de cristalinidade do algodão e encontrou um valor de 85\%, já Park e colaboradores (PARK et al., 2010) usando o método da subtração de picos encontraram um valor ao redor de $81 \%$.

Após a lavagem, as amostras de algodão foram imersas por 30 minutos em uma solução contendo HTMA e nitrato de prata para a deposição das nanopartículas de prata. Depois da retirada da 
umidade excessiva com um papel toalha, as amostras foram secas em chapa de aquecimento, pois o aumento da temperatura leva à decomposição do HTMA e à dissociação do nitrato de prata, como mostrado nas equações 3 (WANG et al., 2010) e 4 (VELAYUTHAM et al., 2016).

$$
\begin{gathered}
\left(\mathrm{CH}_{2}\right)_{6} \mathrm{~N}_{4}+6 \mathrm{H}_{2} \mathrm{O} \leftrightarrow 6 \mathrm{HCHO}+4 \mathrm{NH}_{3} \\
\mathrm{AgNO}_{3}+\mathrm{H}_{2} \mathrm{O} \leftrightarrow \mathrm{Ag}^{+}{ }_{(a q)}+\mathrm{NO}_{3}{ }^{-}
\end{gathered}
$$

Durante o processo de secagem, os íons de prata são reduzidos em prata metálica, através da sua interação com os produtos de decomposição do HTMA e com o aumento da supersaturação da solução devido à evaporação da água. O processo de nucleação e crescimento das NPAg se torna mais favorável, conforme descrito na equação 5 (WANG et al., 2010).

$$
\mathrm{HCHO}+2 \mathrm{Ag}_{(a q)}^{+}+\mathrm{H}_{2} \mathrm{O} \leftrightarrow \mathrm{Ag}^{0}+\mathrm{HCOOH}+2 \mathrm{H}^{+}
$$

Em seguida, as amostras de algodão puro e contendo as partículas de prata passaram por um processo de carbonização e ativação do carvão, a Figura $2 \mathrm{~b}$ mostra o difratograma de raios X destas amostras. O pico alargado encontrado na região entre 15 e $50^{\circ}$, pode ser atribuído à formação de material de estrutura amorfa com planos grafíticos desordenados. Pode-se visualizar a configuração dos picos correspondentes à fase prata metálica 3C, ficha ICDD (PDF01-087-0717), que apresenta estrutura cúbica. A presença destes picos confirma que a prata foi incorporada aos tecidos após o processo de carbonização e ativação (GANDOLFI et al., 2015).Usando-se a equação de Debye-Scherrer foi possível estimar que o tamanho de cristalito de $30,9 \mathrm{~nm}$.

Figura 2 - Difratogramas de Raios X do algodão cru e lavado (a) e do Carvão ativo com e sem as nanopartículas de prata (b).

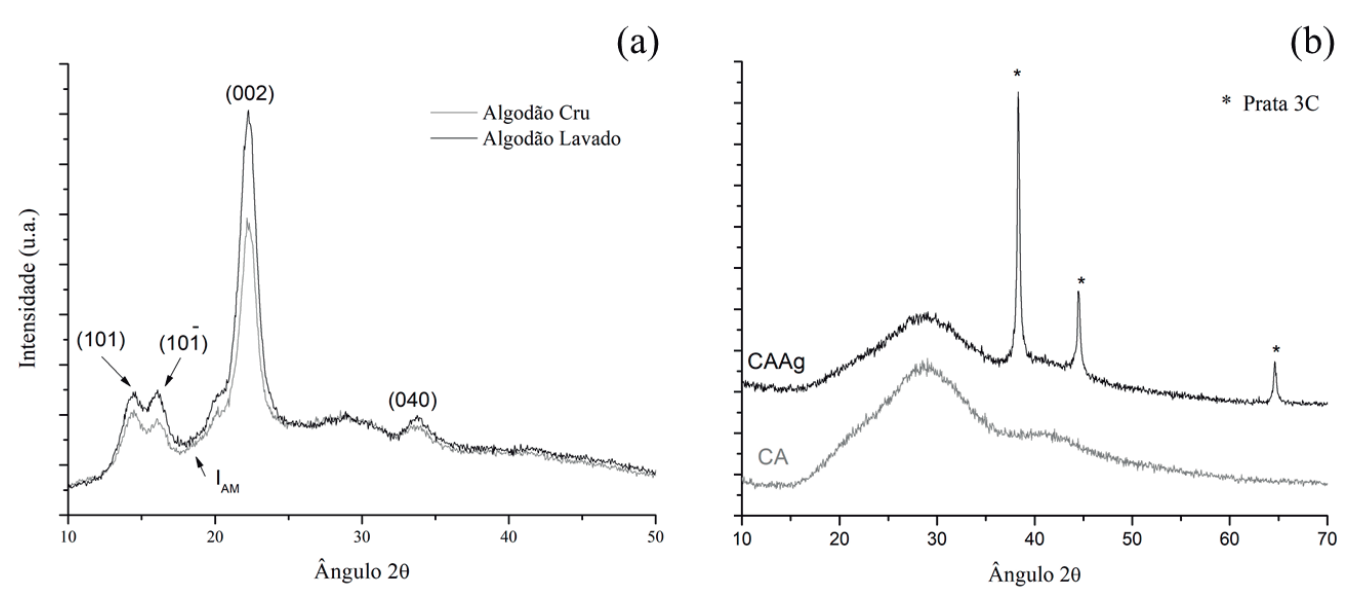

Fonte: Autor

\section{ANÁLISE TERMOGRÁVIMÉTRICA}

A Figura 3 mostra a análise termogravimétrica das amostras de algodão, simulando o processo de carbonização/ativação do tecido. O principal evento de degradação térmica da amostra CA ocorreu entre 250 e $450^{\circ} \mathrm{C}$ e para a amostra CAAg foi entre 300 e $350^{\circ} \mathrm{C}$. Tais perdas de massa envolvem 
reações de despolimerização, desidratação e decomposição das unidades glicosídicas (TEIXEIRA et al., 2010). A massa residual foi de 1,6\% para amostra de CA e 4\% para CAAg, podendo considerar que a massa residual de partículas de prata depositadas sobre o carvão ativo foi ao redor de 2,4\%. $\mathrm{O}$ que permite estimar que a incorporação final de nanopartículas de prata foi de $0,8 \%$ em massa. Barani (2014) adicionou nanopartículas de prata a um tecido de algodão por uma metodologia similar e nos resultados de análise termogravimétrica obteve uma incorporação de 4,03\%.

Figura 3 - Gráfico da análise da perda de massa por termogravimetria.

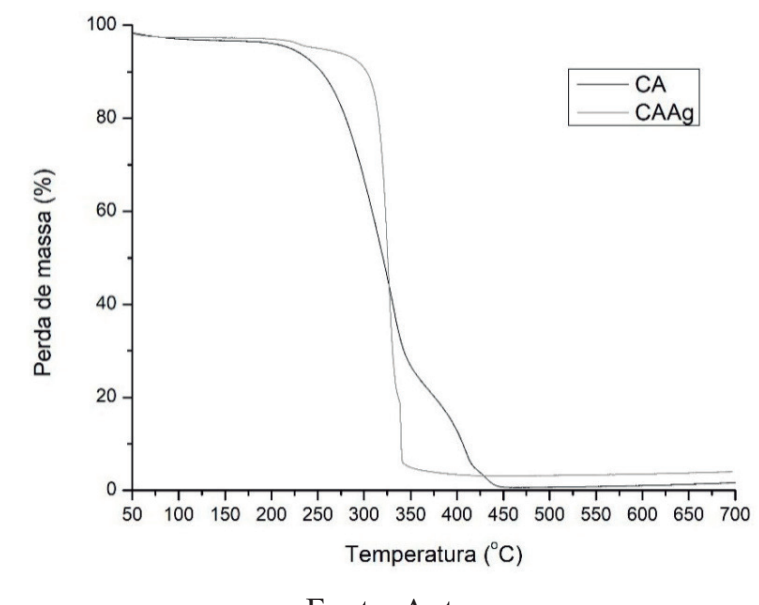

Fonte: Autor

\section{MICROSCOPIA ELETRÔNICA DE VARREDURA - MEV}

A Figura 4, abaixo, indica a morfologia do tecido de algodão lavado (a), do carvão ativo - CA (b), do carvão ativo com nanopartículas de prata CAAg (c), por meio da análise de Microscopia Eletrônica de Varredura.

Figura 4 - Micrografias obtidas por Microscopia Eletrônica de Varredura das amostras (a) Tecido de Algodão Lavado, (b) Carvão ativo - CA, (c) Carvão ativo e NPAg - CAAg.(d) CAAg com ampliação de 10.000X (e) CAAg com ampliação de 25.000X e (f) precipitado da solução da deposição de NPAg.

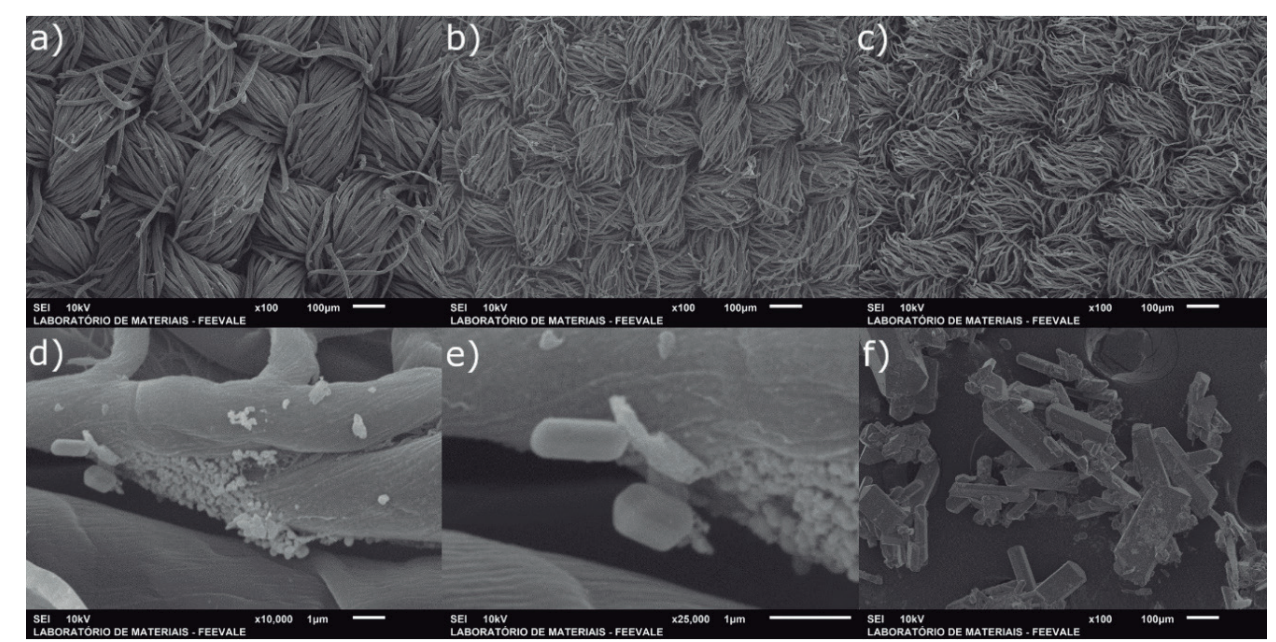

Fonte: Autor 
Analisando-se as micrografias, percebe-se que houve uma diminuição no diâmetro dos fios e das fibras da trama e do urdume do tecido de algodão (Figura 4(a)) quando comparado com os tecidos que sofreram o processo de carbonização (Figuras 4(b) e 4(c)). Examinando as micrografias com ampliação, como mostrado na figura 4(d) é possível observar as nanopartículas de prata de diferentes morfologias depositadas sobre o carvão ativo (CAAg). Averiguando a morfologia, nota-se que as partículas possuem formato de placas e tamanho próximo a 1 micrometro, enquanto as NPAg parecem estar mais aderidas ao CA. Comparando a figura 4(d) e 4(e) com a figura 4(f), verifica-se que há semelhança na morfologia das partículas aderidas ao CA em relação ao precipitado analisado do procedimento da deposição das NPAg.

\section{ESPECTROSCOPIA DE ENERGIA DISPERSIVA - EDS}

Para confirmar que as estruturas apresentadas nas micrografias da Figura 4 correspondem a NPAg, realizou-se a análise por Espectroscopia de Energia Dispersiva (EDS), conforme mostrado na figura 5.

Figura 5 - Análise de EDS e representação das fibras de algodão com CAAg.
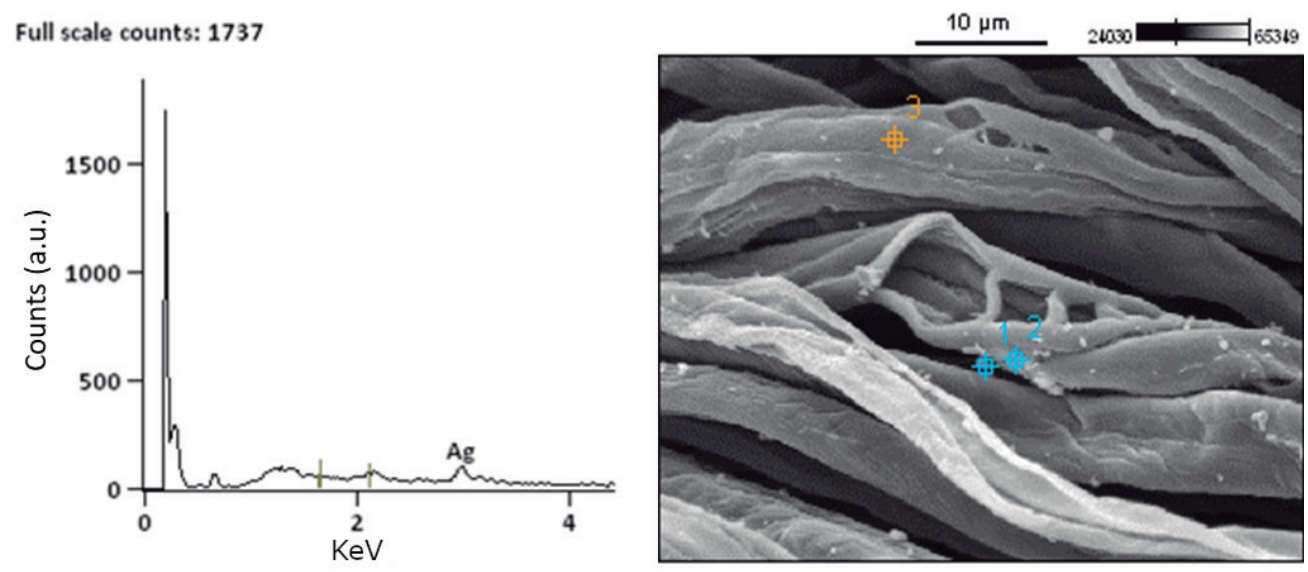

Fonte: Autor

\section{ENSAIO DE BIOFILME}

A Figura 6, mostra o gráfico da capacidade da bactéria Staphylococcus aureus em formar biofilme frente a amostras de tecido 100\% algodão expostas ao processo de deposição de nanopartículas de prata e depois carbonizadas (CAAg), amostra de tecido após lavagem e posterior carbonização (Carvão ativado - CA) e amostra após processo de lavagem (Alg). As amostras foram observadas por espectroscopia UV-Vis em comprimento de onda de $570 \mathrm{~nm}$. 
Figura 6 - Representação de formação de biofilme nas amostras Algodão, CA e CAAg. Sendo CP o controle positivo, ns= diferença não significativa; * =diferença significativa.

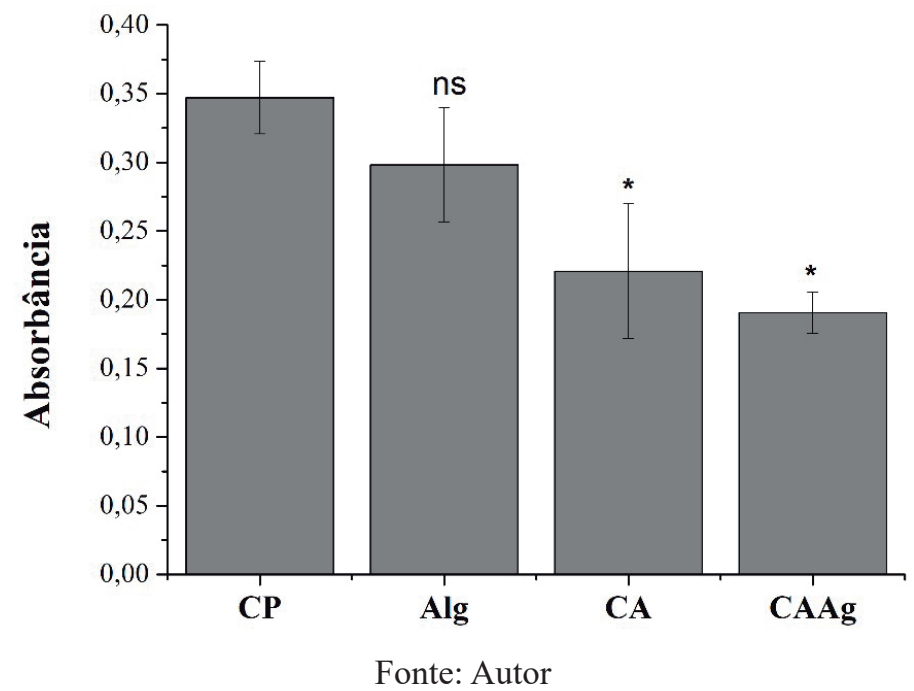

É possível verificar que a utilização de carvão ativo ao invés do tecido de algodão por si só já inibe significativamente a formação de biofilme promovida pela bactéria Staphylococcus aureus, diminuindo a absorbância de 0,30 para 0,22 . Com a adição de partículas de prata a ação inibitória se torna ainda maior, reduzindo a absorbância para 0,19 . Isto sugere o grande potencial que este tipo de material apresenta para prevenir a permanência e proliferação de microrganismos nos EPR's de uso em ambientes de exposição a bactérias desta natureza. De acordo com Parvekar e colaboradores (2020) as nanopartículas de prata estão continuamente liberando íons de prata no microambiente, sendo que a principal razão para a atividade bactericida deste material é o fato deste formar ligações com as estruturas celulares, atrapalhando a replicação do DNA e impedindo a multiplicação da bactéria.

\section{CONCLUSÃO}

Com base nos resultados obtidos, pode-se afirmar que foi desenvolvido um meio filtrante de carvão ativado com incorporação de NPAg com potencial para utilização como equipamento de proteção respiratória para trabalhadores da área da saúde. O procedimento de lavagem resultou em um aumento na cristalinidade do algodão, podendo ser observado através da difração de raios-X. $\mathrm{O}$ processo de carbonização e ativação térmica foi efetivamente realizado nas condições de $850^{\circ} \mathrm{C}$ por 4 horas com fluxo de $100 \mathrm{~mL} / \mathrm{min}$ de argônio. A incorporação da prata pode ser confirmada através da difração de raios X e EDS, sendo que o tamanho de cristalito calculado com a equação de Debye-Scherrer foi de 30,9 nm A análise termogravimétrica confirma que após o processo de carbonização, foi removida toda estrutura orgânica da celulose. Verificou-se também, através do ensaio de formação de biofilme, uma inibição significativa no crescimento de biofilme de bactérias Staphylococcus aureus nas amostras de carvão ativado contendo NPAg. 


\section{REFERÊNCIAS}

ATHAUDA, T. J., LEPAGE, W. S. CHALKER, J. M., OZER R. R., "High density growth of ZnO nanorods on cotton fabric enables access to a flame resistant composite."RSC Adv., v 4, n. 28, p.14582, 2014.

BARANI, H. (2014). Surface activation of cotton fiber by seeding silver nanoparticles and in situ synthesizing ZnO nanoparticles. New J. Chem., 38(9), p. 4365-4370, 2014.

CARÚS, A. L. "Estudo da funcionalização de fibras de algodão através da síntese in-situ de ZnO.” Tese D. Sc,UFRGS, Porto Alegre-RS, 2017.

CETESB. Companhia de Tecnologia e Saneamento Ambiental. Qualidade do ar. Disponível em: $<$ www.cetesb.sp.gov.br> Acesso em dezembro2020.

CHEN, J. H.;CHIU, W. Y. Synthesis of ZnO/polystryrene composites particles by pickering emulsion polymerization. EuropeanPolymerJournal, v. 44, n. 10, p. 3271-3279,2008.

DU T., LIANG J.,DONG N., LU J., FU Y., FANG L.,XIAO S., HAN H.“Glutathione-Capped Ag2S Nanoclusters Inhibit Coronavirus Proliferation through Blockage of Viral RNA Synthesis and Budding ACSApplied Materials \& Interfaces; v. 10, n. 5, p. 4369-4378, 2018.

EL-KADER, F.H.A., HAKEEM, N.A., OSMAN, W.H. et al. Nanosecond Laser Irradiation as New Route for Silver Nanoparticles Precipitation in Glassy Matrix. Silicon 11, p. 377-381, 2019.

GABAS, G. C. C. Análise crítica dos critérios de seleção de respiradores para particulados em ambientes de mineração. Dissertação de Mestrado. Escola Politécnica da USP, São Paulo-SP, 2008.

GALDIERO, S.; FALANGA, A.; VITIELlO, M.; CANTISANI, M.; MARRA, V.; GALDIERO, M. “Silver Nanoparticles as Potential Antiviral Agents.”Molecules, v. 16, p. 8894-8918, 2011.

GANDOLFI, O.R.R., GONÇALVES, G.R.F. SANTOS, C.M.S., BRITO, M.J.P., JESUS, F.W.A., NUNES, G.S. "Síntese e caracterização de carvões ativados produzidos a partir de resíduos de biomassa para servir de suporte de catalizadores bimetálicos." $5^{\circ}$ Congresso Brasileiro de Química, Goiânia - GO, novembro, 2015. 
GUILARDUCI, V.V.S., MESQUITA, J.P., MARTELLI, P.B., GORDULHO, H.F. “Adsorção de fenol sobre carvão ativado em meio alcalino" Química Nova, v. 29, n. 6, PP. 1226-1232, junho, 2006.

HUIDOBRO, A; PASTOR, A. C.; REINOSO RODRÍGUEZ; "Preparation of activated carbon cloth from viscous rayon part IV”. Chemical activation. CarbonJournal, v. 39, n. 3, p. 389-398, march, 2001.

MATSUSHITA, A. F. Y. "Preparação e caracterização de nanopartículas de Ag e ZnO e incorporação em fibras de tecido de algodão.” Tese de D. Sc., Universidade Estadual de Ponta Grossa - PR, 2014.

NAKAMURA S.; SATO M.; SATO Y.; ANDO N.; TAKAYAMA T.; FUJITA M.; ISHIHARA M. "Synthesis and application of silver nano particles (AG NPs) for the prevention of infection in healthcare workers."Int J Mol Sci, v. 20, n 15, p. 3620, august, 2019.

PARIKH D. V., THIBODEAUX D. P.,CONDON B. "X-Ray crystallinity of bleached and cross-linked cottons.’TextileResearchJournal, v. 77, n. 8, p. 612-616, august, 2007.

PARK S, BAKER J. O., HIMMEL M. E., PARILLA P. A., JOHNSON D K. “Crystallinity index: measurement techniques and their impact on interpreting cellulose performance."Biotechnology for Biofuels, v. 3, n.10, p. 2-10, may, 2010.

PARVEKAR, P., PALASKAR, J., METGUD, S., MARIA, R., DUTTA, S.The minimum inhibitory concentration (MIC) and minimum bactericidal concentration (MBC) of silver nanoparticles against Staphylococcus aureus, Biomaterial Investigations in Dentistry, 7:1, p. 105-109, 2020.

PEREIRA, M. O. B. O. “Comparação da eficácia de dois biocidas (carbamato e glutaraldeído) em sistemas de biofilme.”Tese de D. Sc., Braga-Portugal, 2001.

SANTANA LL, SARQUIS LMM, MIRANDA FMA, KALINKE LP, FELLI VEA, MINIEL VA. Health indicators of workers of the hospital area.Rev Bras Enferm [Internet].;69(1):23-32, 2016.

SONDI I., SALOPEK-SONDI B. "Silver nanoparticles as antimicrobialagent: A case studyon E. coli as a model for Gram-negativebacteria”J. ColloidInterfaceSci.; 275:177-182; 2004.

SPELCE, D., REHAK, T. R., METZLER, R. W., \& JOHNSON, J. S. History of U.S. Respirator Approval. Journal of the International Society for Respiratory Protection, 35(1), p. 35-46, 2018. 
STEPANOVIC, S.; VUKOVIC, D.; HOLA, V.; BONAVENTURA, G.; DJUKIC.; IRKOVIC, I.; RUZICKA, F. “Quantification of biofilm in microtiter plates: overview of testing conditions and practical recommendations for assessment of biofilm production by staphylococci"APMIS, v. 115, n. 8, p. 891-899,2007.

SWITZERLAND.INTERNATIONAL LABOUR ORGANIZATION, Safety and health at the heart of the future of work.Disponível em: https://bit.ly/3E2W1dv. Acesso em: julho de 2021.

TEIXEIRA, E. M.; OliveirA, C. R.; MATTOSO L. H. C.; CORREA, A. C.; PALADIN, P. D. "Nanofibras de algodão obtidas sob diferentes condições de hidrólise ácida." Polímeros, v. 20, n. 4, p. 264-268, novembro, 2010.

VELAYUTHAM K.; RAMANIBAIR. "Larvicidal activity of synthesized silvernanoparticles using isoamyl acetate identifiedin Annona squamosa leaves against Aedes aegyptiand Culex quinquefasciatus."The Journal of Basic \& Applied Zoology, v. 74, p. 16-22, 2016.

WANG Y. F.; YAO J. H.; JIA G.; LEI H. “Optical Prosperities of Zn-O composition Nanofilm Synthesized by Bath Deposition.”Acta Physica Polonica A, v. 119, n. 3, p. 451-454, June, 2010. 